Chem. Phys. Lett.

\title{
Vibrational Scaling Factors for Transition Metal Carbonyls
}

\author{
M. K. Assefa, ${ }^{\dagger}$ J. L. Devera, ${ }^{\dagger}$ A. D. Brathwaite, ${ }^{\dagger}$ J. D. Mosley ${ }^{\dagger}$ and M. A. Duncan ${ }^{*} \dagger$ \\ †Department of Chemistry, University of Georgia, Athens, Georgia 30602, U. S. A. \\ College of Science and Mathematics, University of the Virgin Islands, St. Thomas, U.S.V.I., \\ 00802 \\ *Email: maduncan@uga.edu \\ Phone : +1-706-542-1998; Fax: +1-706-542-1234
}

\begin{abstract}
Vibrational frequencies for a selected set of transition metal carbonyl complexes are computed with various forms of density functional theory (B3LYP, BP86, M06, M06-L), employing several different basis sets. The computed frequencies for the carbonyl stretches are compared to the experimental values obtained from gas phase infrared spectra of isolated neutrals and ions. Recommended carbonyl-stretch scaling factors which are developed vary significantly for different functionals, but there is little variation with basis set. Scaled frequencies compared to experimental spectra for cobalt and tantalum carbonyl cations reveal additional variations in multiplet patterns and relative band intensities for different functionals.
\end{abstract}

(C) 2015. This manuscript version is made available under the Elsevier user license http://www.elsevier.com/open-access/userlicense/1.0/ 


\section{Introduction}

Metal carbonyls are ubiquitous throughout inorganic chemistry and homogeneous catalysis, and are also used in practical technology such as photolithography [1-6]. Vibrational spectroscopy in the $\mathrm{C}-\mathrm{O}$ stretch is well established to probe the structure and bonding in these systems [7]. Conventional metal carbonyls have been studied with IR absorption and Raman spectroscopy [8-19]. Unsaturated and ionized systems have been studied in cryogenic rare-gas matrix isolation environments [20]. In recent developments, ionized complexes have been produced and studied in the gas phase with mass spectrometry and infrared laser photodissociation spectroscopy [21-33]. Throughout these various experimental studies, computational work has investigated the geometries, electronic structure and bonding properties of carbonyl systems [3,4,20-33]. These calculations are necessarily harmonic, and vibrational spectra are scaled to account for anharmonicity. Unfortunately, widely used vibrational scaling factors were developed primarily for organic molecules using higher frequency vibrational modes (e.g., C-H stretches) [34-37] and these factors may not work well for lower frequency modes of inorganics. Moreover, density functional theory methods used most often for transition metal systems provide very different frequencies depending on the functional and basis sets employed [38-40]. To address these issues, we have performed a systematic study of vibrational scaling for transition metal carbonyl complexes. We focus on the $\mathrm{C}-\mathrm{O}$ stretch vibrations where the most experimental data is available. We limit the study to gas phase data, where the effects of solvents, counter ions, or matrix environments are eliminated. We present here a study using the DFT methods B3LYP, BP86, M06, and M06-L, all applied to an experimental data set of 20 complexes including well-known neutrals and ions with resolved infrared bands. Recommended scaling factors for each method are determined. 
The vibrational frequencies in transition metal carbonyls are usually compared to the fundamental stretch vibration of the isolated CO molecule, which occurs at $2143 \mathrm{~cm}^{-1}$ [41]. The well-known effects of $\sigma$ donation and $\pi$ back-bonding govern the charge-transfer between ligand and metal, causing significant shifts of the $\mathrm{C}-\mathrm{O}$ stretching frequency upon metal binding $[3,4,7,20,24]$. The resulting frequencies are highly diagnostic for the nature of the bonding; the number and pattern of IR active modes provides specific structural information. In "classical" carbonyls, $\pi$ back-bonding is more important than $\sigma$ donation, resulting in a shift of the $\mathrm{C}-\mathrm{O}$ stretch to lower frequency (a red shift) than that of the isolated CO molecule. In "non-classical" carbonyls, usually those with filled $d$ shells, back donation is less and shifts to higher frequencies (blue shifts) result. These effects are documented for many complexes, and computational studies support the charge-transfer basis for the interpretation. Carbonyl vibrations also vary substantially with the electronic state and spin of the system [24,28].

Measured vibrational band patterns, in combination with the predictions of theory, are often successful in assigning structures and electronic configurations to new metal carbonyls. However, homoleptic carbonyls with symmetric structures often have only a single IR-active $\mathrm{C}-\mathrm{O}$ stretch. Distinguishing between symmetric structures (e.g., square planar vs tetrahedral), or between two spin configurations of symmetric structures, requires reliable and un-biased vibrational scaling. These effects were investigated previously at lower levels of theory for a data set containing mixed gas-phase and condensed-phase data [42]. The scale factors developed here employ the DFT functionals commonly used in present-day research and apply them to spectra measured only for isolated complexes in the gas phase. Hopefully these data be useful for future computational and experimental studies of inorganic systems. 


\section{Experimental}

The harmonic $\mathrm{C}-\mathrm{O}$ stretching frequencies of transition metal carbonyl ions and neutrals were computed using the Gaussian 09 computational package [43] and density functional theory (DFT). The B3LYP, BP86, M06 and M06-L functionals were used with the LANL2DZ, LANL2TZ and Def2-TZVP basis sets for the metal atoms and ions and the TZP basis set for carbon and oxygen. Effective core potentials (ECP) were used for all calculations. For each functional/basis set combination, optimized structures and the corresponding unscaled $\mathrm{C}-\mathrm{O}$ stretching frequencies were determined. The average scaling factor needed to bring each theoretical $\mathrm{C}-\mathrm{O}$ frequency into agreement with the experimental data was determined for each functional/basis set combination. For each computational model and for each observed vibrational band in the data set (Table 1), we computed the ratio between the experimental and computed frequencies. The distribution of ratios across vibrations (but within one computational model) were then characterized by a mean value. Then the computed frequencies were multiplied by this mean value and the result subtracted from the observed frequency to obtain a distribution of predictive errors associated with the mean scaling factor. This error distribution is characterized by a root-mean-square (RMS) value. For comparison to selected experimental data, the theoretical spectra are given a $\sim 10 \mathrm{~cm}^{-1}$ FWHM linewidth.

\section{Results and Discussion}

Tables 1-4 present the $\mathrm{C}-\mathrm{O}$ stretch vibrational frequencies resulting from computational studies with different functionals and basis sets for various metal carbonyl neutral and ion complexes. These tables also present the data for the B3LYP, BP86, M06 and M06-L functionals, respectively. This set of carbonyl complexes was chosen because infrared spectra have been reported for each system in the gas phase, in the absence of any perturbations from 
solvents, counter ions or matrix environments. In each case, the structures determined were found to have no imaginary frequencies, and were consistent with those reported in the previous experimental and computational work. The carbonyl stretch frequencies shown in these tables are the harmonic values resulting directly from the computations.

Table 5 presents the optimized values for the vibrational scaling factors determined by averaging over the factor required for each of the complexes in the data set to bring the experimental and computed data into agreement. The experimental data measured for gas phase neutral complexes using absorption spectroscopic methods typically have uncertainties less than $1 \mathrm{~cm}^{-1}$ [8-19], whereas the newer ion data measured with photodissociation spectroscopy have larger uncertainties of $1-2 \mathrm{~cm}^{-1}$ arising from the predissociation linewidths [21-33]. However, for this analysis, we use the reported frequencies for all of these data with equal weighting. As shown in the table, there is significant variation in the scaling factors derived for different functionals, but virtually no difference for the values of a given functional with different basis sets. The values for the B3LYP and M06-L functionals are both near 0.97, with a slightly smaller value for the M06 functional and a value slightly larger than 1.0 for BP86. We previously derived a scaling factor of 0.971 for the B3LYP/LANL2DZ functional/basis combination using a more limited set of the known neutral carbonyls $\mathrm{Ni}(\mathrm{CO})_{4}, \mathrm{Fe}(\mathrm{CO})_{5}$, and $\mathrm{Cr}(\mathrm{CO})_{6}$ [31]. This value is quite similar to that derived here using a much larger set of experimental data. In the only other previous work, Yu, Srinivas and Schwartz derived a value of 0.955 for B3LYP with a much smaller basis set [42], while investigating a mixture of gasphase and condensed-phase experimental systems.

It is also interesting to compare the scaling factors derived here for metal carbonyls to those determined previously for higher frequency vibrations. Radom and coworkers performed systematic studies of the $\mathrm{C}-\mathrm{H}$ stretches for data sets of organic molecules $[34,35]$. The basis sets 
were different from those used here, but at the B3LYP/6-311+G(d,p) level they derived a factor of 0.9689, quite close to the values determined here for the B3LYP data. It has been noted in previous studies that different scaling factors are often required for high frequency versus low frequency vibrations, with a break-point often selected at about $2000 \mathrm{~cm}^{-1}[36,37]$. The carbonyl stretch vibrations lie close to this cutoff, and so it might be expected that a different scaling factor would be required here. However, the factor derived here for the carbonyl stretches is virtually the same as that recommended for the higher frequency vibrations.

In addition to the average scaling factors, it is also interesting to compare the performance of different functionals for vibrational patterns in the carbonyl stretching region. For this investigation, we have chosen the carbonyl stretch spectra for two representative systems which each exhibit multiplet patterns in this region rather than a single vibrational band. $\mathrm{Co}(\mathrm{CO})_{5}{ }^{+}$is the fully-coordinated complex for this metal, with an 18 -electron configuration, and the trigonal bipyramid structure [23]. It is isoelectronic to and has the same structure as $\mathrm{Fe}(\mathrm{CO})_{5}$. It has two distinct $\mathrm{C}-\mathrm{O}$ stretches corresponding nominally to the axial and equatorial ligands. $\mathrm{Ta}(\mathrm{CO})_{7}{ }^{+}$is another example of a fully coordinated complex with an 18-electron configuration. It has the capped-octahedral structure, with five distinct $\mathrm{C}-\mathrm{O}$ stretches [24]. Figures 1 and 2 show the experimental spectra for these two complexes compared to the spectra predicted by theory using different functionals and the same basis set (Def2-TZVP). In each case, the spectra are scaled using the optimized scaling factor for that functional and basis set.

As shown in Figure 1, all functionals find two distinct carbonyl stretches for the $\mathrm{Co}(\mathrm{CO})_{5}{ }^{+}$complex, but the intensity ratios of the two bands are somewhat different for each functional, as are the relative spacings of the bands. The experimental spacing between the two bands is $10 \mathrm{~cm}^{-1}$, which is reproduced best by BP86 $\left(9 \mathrm{~cm}^{-1}\right)$ and M06-L $\left(12 \mathrm{~cm}^{-1}\right)$. The spacing with M06 is much lower $\left(7 \mathrm{~cm}^{-1}\right)$ and that with B3LYP is much higher $\left(17 \mathrm{~cm}^{-1}\right)$. All functionals 
find the lower frequency band to be more intense, but BP86 has the best relative intensities. Similar variations are found for the $\mathrm{Ta}(\mathrm{CO})_{7}^{+}$spectrum. All functionals find a five-band pattern that is a recognizable match to the experiment, and all find the band second from lowest frequency $\left(2067 \mathrm{~cm}^{-1}\right.$ in the experiment) to be the most intense. However, all four functionals predict the multiplet containing the four most intense peaks to be more closely spaced than it actually is. All four find the $2168 \mathrm{~cm}^{-1}$ band to be much weaker in relative intensity than it actually is. In this case, B3LYP best reproduces the overall multiplet width and relative intensities, whereas M06-L provides the poorest match to the experiment. These multiplet spacings and relative intensity data clearly show that it takes more than a single frequency scaling factor to reproduce the true effects of anharmonicity on carbonyl vibrations.

There is much discussion in the quantum chemistry literature about the advantages and disadvantages of different computational methods. Density functional theory is often noted to give poorer results than other methods such as MP2 or $\operatorname{CCSD}(\mathrm{T})$, with respect to the computation of molecular energetics. However, it is now well understood that DFT is the method of choice for studies of transition metal complexes and materials because of its reduced demands on computational resources [38-40]. There has also been much discussion about different DFT functionals and which of these give the best molecular energetics [38-40]. However, there has been much less attention given to the performance of different DFT functionals with respect to vibrational spectroscopy. The present study is by no means comprehensive. It does not examine metal-ligand stretch vibrations which occur at much lower frequencies and have been the subject of other studies [44]. However, it does examine the important class of homoleptic metal carbonyls, which are representative of metal-ligand complexes. In this selected group of systems, we find that the application of scaling factors does produce theoretical vibrations for several different functionals and basis sets that provide 
qualitative agreement with measured spectra. However, the details of multiplet patterns and relative intensities are more challenging to describe and it is not clear that any of the present functionals has a clear advantage over the others in this respect.

\section{Conclusions}

Computational studies are carried out on a data set of 20 transition metal carbonyl neutral and cation complexes for which vibrational spectra have been measured in the gas phase. Four representative DFT functionals are investigated with three different basis sets each. The structures and lowest electronic states obtained for these complexes are all consistent with earlier results. The computed vibrational frequencies for these complexes are compared to those measured experimentally, and the combined results are used to derive recommended vibrational scaling factors for each method. We find only a small variation with different basis sets for each method, but a more significant variation in scaling factors for different functionals. Surprisingly, the scaling factors determined are not very different from those derived previously for higher frequency vibrations of organic molecules. It therefore seems safe to assume that DFT methods other than those used here could also employ scaling factors derived previously for higher frequency vibrations. Although the agreement with experiment is good when the presently derived scaling factors are employed, there is still significant variation in the spacings and relative intensities when multiplet band patterns are examined. On the basis of the limited data investigated in this way, none of the four functionals has a clear advantage in performance over the others in the description of vibrational spectra. 


\section{Acknowledgments}

We acknowledge generous support for this work from the U.S. Department of Energy, Office of Science, Basic Energy Sciences, Division of Chemical, Geological, and Biosciences (grant no.

DE-FG02-96ER14658). A. D. B and J. L. D. wish to acknowledge salary support from the National Science Foundation through grant no. HRD-1505095. 


\section{References}

[1] M. Wrighton, "The photochemistry of metal carbonyls," Chem. Rev. 74 (1974) 401.

[2] J. E. Huheey, E. A. Keiter, R. L. Keiter, Inorganic Chemistry Principles of Structure and Reactivity, Harper Collins, New York, 1993.

[3] F. Aubke, C. Wang, "Carbon monoxide as a $\sigma$-donor ligand in coordination chemistry," Coord. Chem. Rev. 137 (1994) 483.

[4] G. Frenking, N. Fröhlich, "The nature of the bonding in transition-metal compounds," Chem. Rev. 100 (2000) 717.

[5] R. H. Crabtree, The Organometallic Chemistry of the Transition Metals, $5^{\text {th }}$ ed., Wiley, Hoboken, NJ, 2009.

[6] I. B. Bersuker, Electronic Structure and Properties of Transition Metal Compounds, $2^{\text {nd }}$ ed., Wiley, Hoboken, NJ, 2010.

[7] K. Nakamoto, Infrared and Raman Spectra of Inorganic and Coordination Compounds, Parts $A$ and $B, 5^{\text {th }}$ ed., John Wiley, New York, 1997.

[8] S. L. Shufler, H. W. Sternberg, R. A. Friedel, "Infrared spectrum and structure of chromium hexacarbonyl, Cr(CO)6," J. Am. Chem. Soc. 78 (1956) 2687.

[9] M. F. O'Dwyer, "Infrared spectra and normal coordinate analysis of iron pentacarbonyl," J. Molec. Spec. 2 (1958) 144.

[10] H. Stammerich, K. Kawai, Y. Tavares, P. Krumholz, J. Behmoiras, S. Bril, "Raman spectra of metal carbonyl compounds. II. Raman spectra, structure, and force constants of cobalt and iron tetracarbonylate anions," J. Chem. Phys. 32 (1960) 1482.

[11] W. F. Edgell, J. I. Lyford, "Laser Raman and infrared spectra of the tetrahedral $\mathrm{Co}(\mathrm{CO})_{4}{ }^{-}$ ion," J. Chem. Phys. 52 (1970) 4329. 
[12] G. Bouquet, M. Bigorgne, "Constantes de force du nickel carbonyle $\mathrm{Ni}(\mathrm{CO})_{4}, "$ Spectrochim. Acta Part A 27 (1971) 139.

[13] L. H. Jones, R. S. McDowell, M. Goldblatt, "Potential constants of iron pentacarbonyl from vibrational spectra of isotopic species," J. Chem. Phys. 57 (1972) 2050.

[14] B. Beagley, D. G. Schmidling, "A re-evaluation of the molecular structure of iron pentacarbonyl," J. Molec. Struct. 22 (1974) 5466.

[15] P. L. Bogdan, E. Weitz, "A transient infrared spectroscopy study of coordinatively unsaturated ruthenium carbonyls," J. Am. Chem. Soc. 111 (1989) 3163.

[16] P. L. Bogdan, E. Weitz, "A transient infrared spectroscopy study of coordinatively unsaturated osmium carbonyl compounds," J. Am. Chem. Soc. 112 (1990) 639.

[17] Y. Ishikawa, C. E. Brown, P. A. Hackett, D. M. Rayner, "Excimer laser photolysis of group 6 metal carbonyls in the gas phase," J. Phys. Chem. 94 (1990) 2404.

[18] Y. Ishikawa, P. A. Hackett, D. M. Rayner, "Excimer laser photolysis of gas-phase tungsten hexacarbonyl," J. Phys. Chem. 92 (1988) 3863.

[19] Y. Ishikawa, P. A. Hackett, D. M. Rayner, "Excimer laser photolysis of vanadium hexacarbonyl: Time-resolved infrared studies of gas-phase $\mathrm{V}(\mathrm{CO})_{\mathrm{x}}(\mathrm{x}=5-2)$, , J. Am. Chem. Soc. 109 (1987) 6644.

[20] M. Zhou, L. Andrews, C. W. Bauschlicher, Jr., "Spectroscopic and theoretical investigation of vibrational frequencies in binary unsaturated transition-metal carbonyl cations, neutrals, and anions," Chem. Rev. 101 (2001) 1931.

[21] J. Velasquez III, B. Njegic, M. S. Gordon, M. A. Duncan, "IR photodissociation spectroscopy and theory of $\mathrm{Au}^{+}(\mathrm{CO})_{\mathrm{n}}$ complexes: Nonclassical carbonyls in the gas phase," J. Phys. Chem. A 112 (2008) 1907. 
[22] J. Velasquez III, M. A. Duncan, "IR photodissociation spectroscopy of gas phase $\mathrm{Pt}^{+}(\mathrm{CO})_{\mathrm{n}}(\mathrm{n}=4-6), "$ Chem. Phys. Lett. 461 (2008) 28.

[23] A. M. Ricks, J. M. Bakker, G. E. Douberly, M. A. Duncan, "Infrared spectroscopy and structures of cobalt carbonyl cations, $\operatorname{Co}(\mathrm{CO})_{\mathrm{n}}^{+}(\mathrm{n}=1-9), "$ J. Phys. Chem. A 113 (2009) 4701.

[24] A. M. Ricks, Z. D. Reed, M. A. Duncan, "Seven-coordinate homoleptic metal carbonyls in the gas phase," J. Am. Chem. Soc. 131 (2009) 9176.

[25] Z. D. Reed, M. A. Duncan, "Infrared spectroscopy and structures of manganese carbonyl cations, $\mathrm{Mn}(\mathrm{CO})_{\mathrm{n}}{ }^{+}(\mathrm{n}=1-9), "$ J. Am. Soc. Mass Spectrom. 21 (2010) 739.

[26] A. M. Ricks, Z.E. Reed, M.A. Duncan, "Infrared spectroscopy of mass-selected metal carbonyl cations," J. Mol. Spec. 266 (2011) 63.

[27] A. D. Brathwaite, Z. D. Reed, M. A. Duncan, "Infrared photodissociation spectroscopy of copper carbonyl cations," J. Phys. Chem. A. 115 (2011) 10461.

[28] A. M. Ricks, A. D. Brathwaite, M. A. Duncan, "Coordination and spin states in vanadium carbonyl complexes $\left(\mathrm{V}(\mathrm{CO})_{\mathrm{n}}{ }^{+}, \mathrm{n}=1-7\right)$ revealed with IR spectroscopy," J. Phys. Chem. A 117 (2013) 1001.

[29] A. D. Brathwaite, M. A. Duncan, "Infrared photodissociation spectroscopy of saturated group IV (Ti, Zr, Hf) metal carbonyl cations," J. Phys. Chem. A 117 (2013) 11695.

[30] A. D. Brathwaite, J. A. Maner, M. A. Duncan, "Testing the limits of the 18-electron rule: The gas-phase carbonyls of $\mathrm{Sc}^{+}$and $\mathrm{Y}^{+}$," Inorg. Chem. 53 (2014) 1166.

[31] G. J. Wang, C. X. Chi, J. M. Cui, X. P. Xing, M. Zhou, "Infrared photodissociation spectroscopy of mononuclear iron carbonyl anions," J. Phys. Chem. A 116 (2012) 2484. 
[32] C. X. Chi, J. M. Cui, X. P. Xing, G. J. Wang, Z. P. Liu, M. Zhou, "Infrared photodissociation spectroscopy of trigonal bipyramidal 19-electron $\mathrm{Ni}(\mathrm{CO})_{5}{ }^{+}$cation," Chem. Phys. Lett. 542 (2012) 33.

[33] G. J. Wang, J. M. Cui, C. X. Chi, X. J. Zhou, Z. H. Li, X. P. Xing, M. Zhou, "Bonding in homoleptic iron carbonyl cluster cations: A combined infrared photodissociation spectroscopic and theoretical study," Chem. Sci. 3 (2012) 3272.

[34] A. P. Scott, L. Radom, "Harmonic vibrational frequencies: an evaluation of Hartree-Fock, Møller-Plesset, quadratic configuration interaction, density functional theory, and semiempirical scale factors," J. Phys. Chem. 100 (1996) 16502.

[35] J. P. Merrick, D. Moran, L. Radom, "An evaluation of harmonic vibrational frequency scale factors," J. Phys. Chem. A 111 (2007) 11683.

[36] R. D. Johnson III, K. K. Irikawa, R. N. Kacker, R. Kessel, "Scaling factors and uncertainties for ab initio anharmonic vibrational frequencies," J. Chem. Theor. Comp. 6 (2010) 2822.

[37] C. Fábri, T. Szidarovszky, G. Magyarfalvi, G. Tarczay, "Gas-phase and Ar-matrix SQM scaling factors for various DFT functionals with basis sets including polarization and diffuse functions," J. Phys. Chem. A 115 (2011) 4640.

[38] V. Jonas, W. Thiel, "Symmetry force fields for neutral and ionic transition metal carbonyl complexes from density functional theory," J. Phys. Chem. A 103 (1999) 1381.

[39] C. J. Cramer, D. G. Truhlar, "Density functional theory for transition metals and transition metal chemistry," Phys. Chem. Chem. Phys. 11 (2009) 10757.

[40] S. Shil, D. Bhattacharya, S. Sarker, A. Misra, "Performance of the widely used Minnesota density functionals for the predictions of heats of formations, ionization potentials of 

Diatomic Molecules, Van Nostrand Reinhold Co., 1979.

[42] L. Yu, G. N. Srinivas, M. Schwartz, "Scale factors for $\mathrm{C} \equiv \mathrm{O}$ vibrational frequencies in organometallic complexes," J. Molec. Struc. (Theochem) 625 (2003) 215.

[43] M. J. Frisch, G. W. Trucks, H. B. Schlegel, G. E. Scuseria, M. A. Robb, J. R. Cheeseman, G. Scalmani, V. Barone, B. Mennucci, G. A. Petersson, et al. Gaussian 09 (Revision D.01), Gaussian, Inc., Wallingford CT, 2009.

[44] C. Latouche, F. Palazzetti, D. Skouteris, V. Barone, "High-accuracy vibrational computations for transition-metal complexes including anharmonic corrections: Ferrocene, ruthenocene and osmocene as test cases," J. Chem. Theor. Comp. 10 (2014) 4565. 
Table 1. Electronic ground states and experimental and theoretical frequencies $\left(\mathrm{cm}^{-1}\right)$ for metal carbonyl complexes computed using DFT/B3LYP.

\begin{tabular}{|c|c|c|c|c|c|}
\hline Complex & Spin State & Experiment & $\begin{array}{l}\text { LANL2DZ } \\
\text { TZP }\end{array}$ & $\begin{array}{l}\text { LANL2TZ } \\
\text { TZP }\end{array}$ & $\begin{array}{l}\text { Def2-TZVP } \\
\text { TZP }\end{array}$ \\
\hline $\mathrm{Ti}(\mathrm{CO})_{6}^{+}$ & quartet & 2110 [30] & 2184 & 2180 & 2179 \\
\hline $\mathrm{V}(\mathrm{CO})_{6}{ }^{+}$ & triplet & 2097 [29] & 2183,2186 & 2182,2184 & 2180,2182 \\
\hline $\mathrm{V}(\mathrm{CO})_{6}$ & doublet & 1989 [20] & 2065,2068 & 2063,2066 & 2062,2065 \\
\hline $\mathrm{Cr}(\mathrm{CO})_{6}$ & singlet & $2000[8]$ & 2073 & 2074 & 2070 \\
\hline $\mathrm{Mn}(\mathrm{CO})_{6}^{+}$ & singlet & 2115 [26] & 2195 & 2197 & 2192 \\
\hline $\mathrm{Fe}(\mathrm{CO})_{5}{ }^{+}$ & doublet & 2123 [34] & 2210,2215 & 2209,2214 & 2206,2211 \\
\hline \multirow[t]{2}{*}{$\mathrm{Fe}(\mathrm{CO})_{5}$} & singlet & 2016 & 2082,2111 & 2081,2111 & 2078,2106 \\
\hline & & 2038 [9] & & & \\
\hline \multirow[t]{2}{*}{$\mathrm{Co}(\mathrm{CO})_{5}^{+}$} & singlet & 2140 & 2215,2233 & 2216,2232 & 2213,2227 \\
\hline & & $2150[24]$ & & & \\
\hline $\mathrm{Ni}(\mathrm{CO})_{4}$ & singlet & 2061 [12] & 2125 & 2124 & 2120 \\
\hline \multirow[t]{2}{*}{$\mathrm{Ni}(\mathrm{CO})_{5}^{+}$} & doublet & 2169 & 2244,2266 & 2239,2261 & 2236,2259 \\
\hline & & 2183 [33] & & & \\
\hline $\mathrm{Cu}(\mathrm{CO})_{4}^{+}$ & singlet & 2198 [28] & 2277 & 2277 & 2273 \\
\hline $\mathrm{Y}(\mathrm{CO})_{8}{ }^{+}$ & singlet & 2087 [31] & 2165,2167 & 2165,2167 & 2163, 2166 \\
\hline $\mathrm{Zr}(\mathrm{CO})_{6}{ }^{+}$ & quartet & 2094 [30] & 2164 & 2162 & 2157 \\
\hline \multirow[t]{3}{*}{$\mathrm{Nb}(\mathrm{CO})_{7}^{+}$} & singlet & 2057,2075 & 2136,2149 & 2132,2147 & 2131,2143 \\
\hline & & 2100,2125 & 2168,2191 & 2165,2190 & 2162,2186 \\
\hline & & 2169 [25] & 2243 & 2241 & 2240 \\
\hline $\mathrm{Mo}(\mathrm{CO})_{6}$ & singlet & 2003 [18] & 2070 & 2068 & 2066 \\
\hline
\end{tabular}




$\begin{array}{llllll}\mathrm{Ru}(\mathrm{CO})_{5} & \text { singlet } & 2015, & 2077,2114 & 2075,2111 & 2073,2109 \\ & & 2045[16] & & \\ \mathrm{Hf}(\mathrm{CO})_{6}{ }^{+} & \text {quartet } & 2075[30] & 2145 & 2143 & 2141 \\ \mathrm{Ta}(\mathrm{CO})_{7}{ }^{+} & \text {singlet } & 2056,2067, & 2133,2141, & 2130,2138, & 2126,2137, \\ & & 2089,2113, & 2158,2179, & 2157,2177, & 2153,2176, \\ & & 2168[25] & 2243 & 2241 & 2237 \\ \mathrm{~W}(\mathrm{CO})_{6} & \text { singlet } & 2000[19] & 2063 & 2061 & 2058 \\ \mathrm{Os}(\mathrm{CO})_{5} & \text { singlet } & 2008, & 2069,2111 & 2065,2107 & 2060,2104 \\ & & 2046[17] & & & \end{array}$


Table 2. Electronic ground states and experimental and theoretical frequencies $\left(\mathrm{cm}^{-1}\right)$ for metal carbonyl complexes computed using DFT/BP86.

\begin{tabular}{|c|c|c|c|c|c|}
\hline Complex & Spin State & Experiment & $\begin{array}{l}\text { LANL2DZ } \\
\text { TZP }\end{array}$ & $\begin{array}{l}\text { LANL2TZ } \\
\text { TZP }\end{array}$ & $\begin{array}{l}\text { Def2-TZVP } \\
\text { TZP }\end{array}$ \\
\hline $\operatorname{Ti}(\mathrm{CO})_{6}^{+}$ & quartet & 2110 [30] & 2083 & 2079 & 2076 \\
\hline $\mathrm{V}(\mathrm{CO})_{6}^{+}$ & triplet & 2097 [29] & 2079,2081 & 2078,2080 & 2074, 2077 \\
\hline $\mathrm{V}(\mathrm{CO})_{6}$ & doublet & 1989 [20] & 1980,1982 & 1980,1982 & 1977,1979 \\
\hline $\mathrm{Cr}(\mathrm{CO})_{6}$ & singlet & $2000[8]$ & 1994 & 1994 & 1990 \\
\hline $\mathrm{Mn}(\mathrm{CO})_{6}^{+}$ & singlet & 2115 [26] & 2097 & 2096 & 2092 \\
\hline $\mathrm{Fe}(\mathrm{CO})_{5}{ }^{+}$ & doublet & 2123 [34] & 2103,2109 & 2103,2108 & 2098,2102 \\
\hline \multirow[t]{2}{*}{$\mathrm{Fe}(\mathrm{CO})_{5}$} & singlet & 2016 & 2007,2025 & 2005,2023 & 2000,2018 \\
\hline & & 2038 [9] & & & \\
\hline \multirow[t]{2}{*}{$\mathrm{Co}(\mathrm{CO})_{5}^{+}$} & singlet & 2140 & 2117,2126 & 2118,2125 & 2112,2120 \\
\hline & & $2150[24]$ & & & \\
\hline $\mathrm{Ni}(\mathrm{CO})_{4}$ & singlet & $2061[12]$ & 2039 & 2041 & 2034 \\
\hline \multirow[t]{2}{*}{$\mathrm{Ni}(\mathrm{CO})_{5}^{+}$} & doublet & 2169 & 2135,2147 & 2132,2141 & 2129,2139 \\
\hline & & 2183 [33] & & & \\
\hline $\mathrm{Cu}(\mathrm{CO})_{4}^{+}$ & singlet & 2198 [28] & 2175 & 2175 & 2171 \\
\hline $\mathrm{Y}(\mathrm{CO})_{8}{ }^{+}$ & singlet & 2087 [31] & 2071,2073 & 2070,2071 & 2068,2070 \\
\hline $\mathrm{Zr}(\mathrm{CO})_{6}^{+}$ & quartet & 2094 [30] & 2069 & 2066 & 2062 \\
\hline \multirow[t]{3}{*}{$\mathrm{Nb}(\mathrm{CO})_{7}^{+}$} & singlet & 2057,2075 & 2044,2057 & 2043,2055 & 2038,2048 \\
\hline & & 2100,2125 & 2071, 2092, & 2063,2083 & 2059,2079 \\
\hline & & 2169 [25] & 2149 & 2148 & 2144 \\
\hline $\mathrm{Mo}(\mathrm{CO})_{6}$ & singlet & 2003 [18] & 1991 & 1988 & 1986 \\
\hline
\end{tabular}




$\begin{array}{llllll}\mathrm{Ru}(\mathrm{CO})_{5} & \text { singlet } & 2015, & 1996,2027 & 1993,2024 & 1991,2024 \\ & & 2045[16] & & \\ \mathrm{Hf}(\mathrm{CO})_{6}{ }^{+} & \text {quartet } & 2075[30] & 2057 & 2054 & 2052 \\ \mathrm{Ta}(\mathrm{CO})_{7}{ }^{+} & \text {singlet } & 2056,2067, & 2045,2054, & 2044,2052, & 2038,2048, \\ & & 2089,2113, & 2066,2084, & 2063,2083, & 2059,2079, \\ & & 2168[25] & 2149 & 2148 & 2144 \\ \mathrm{~W}(\mathrm{CO})_{6} & \text { singlet } & 2000[19] & 1988 & 1986 & 1982 \\ \mathrm{Os}(\mathrm{CO})_{5} & \text { singlet } & 2008, & 1995,2029 & 1990,2026 & 1983,2022 \\ & & 2046[17] & & & \end{array}$


Table 3. Electronic ground states and experimental and theoretical frequencies $\left(\mathrm{cm}^{-1}\right)$ for metal carbonyl complexes computed using DFT/M06.

\begin{tabular}{|c|c|c|c|c|c|}
\hline Complex & Spin State & Experiment & $\begin{array}{l}\text { LANL2DZ } \\
\text { TZP }\end{array}$ & $\begin{array}{l}\text { LANL2TZ } \\
\text { TZP }\end{array}$ & $\begin{array}{l}\text { Def2-TZVP } \\
\text { TZP }\end{array}$ \\
\hline $\mathrm{Ti}(\mathrm{CO})_{6}^{+}$ & quartet & $2110[30]$ & 2211 & 2211 & 2216 \\
\hline \multirow[t]{2}{*}{$\mathrm{V}(\mathrm{CO})_{6}^{+}$} & triplet & 2097 [29] & 2209,2212 & 2208,2211 & 2192,2223 \\
\hline & & & & & 2226 \\
\hline \multirow[t]{2}{*}{$\mathrm{V}(\mathrm{CO})_{6}$} & doublet & 1989 [20] & 2092, 2094, & 2092,2094 & 2092,2095 \\
\hline & & & 2097 & 2097 & 2098 \\
\hline $\mathrm{Cr}(\mathrm{CO})_{6}$ & singlet & $2000[8]$ & 2101 & 2099 & 2105 \\
\hline $\mathrm{Mn}(\mathrm{CO})_{6}^{+}$ & singlet & 2115 [26] & 2218 & 2220 & 2224 \\
\hline $\mathrm{Fe}(\mathrm{CO})_{5}{ }^{+}$ & doublet & $2123[34]$ & 2233,2242 & 2233,2241 & 2237,2242 \\
\hline \multirow[t]{2}{*}{$\mathrm{Fe}(\mathrm{CO})_{5}$} & singlet & 2016 & 2120,2139 & 2118,2135 & 2112,2138 \\
\hline & & 2038 [9] & & & \\
\hline \multirow[t]{2}{*}{$\mathrm{Co}(\mathrm{CO})_{5}^{+}$} & singlet & 2140 & 2251,2257 & 2249,2256 & 2246,2257 \\
\hline & & 2150 [24] & & & \\
\hline $\mathrm{Ni}(\mathrm{CO})_{4}$ & singlet & $2061[12]$ & 2157 & 2158 & 2152 \\
\hline \multirow[t]{2}{*}{$\mathrm{Ni}(\mathrm{CO})_{5}^{+}$} & doublet & 2169 & 2277,2290 & 2275,2288 & 2272,2289 \\
\hline & & 2183 [33] & & & \\
\hline $\mathrm{Cu}(\mathrm{CO})_{4}^{+}$ & singlet & 2198 [28] & 2307 & 2306 & 22302 \\
\hline $\mathrm{Y}(\mathrm{CO})_{8}^{+}$ & singlet & 2087 [31] & 2198,2201 & 2197, 2199 & 2196, 2199 \\
\hline $\mathrm{Zr}(\mathrm{CO})_{6}{ }^{+}$ & quartet & 2094 [30] & 2202 & 2198 & 2194 \\
\hline $\mathrm{Nb}(\mathrm{CO})_{7}^{+}$ & singlet & 2057,2075 & 2168,2180 & 2166, 2179, & 2165,2177 \\
\hline & & 2100,2125 & 2198, 2219, & 2199, 2222, & 2196, 2221, \\
\hline
\end{tabular}




$\begin{array}{llllll} & & 2169[25] & 2271 & 2275 & 2273 \\ \mathrm{Mo}(\mathrm{CO})_{6} & \text { singlet } & 2003[18] & 2102 & 2099 & 2096 \\ \mathrm{Ru}(\mathrm{CO})_{5} & \text { singlet } & 2015, & 2107,2139 & 2105,2136 & 2103,2135 \\ & & 2045[16] & & & \\ \mathrm{Hf}(\mathrm{CO})_{6}{ }^{+} & \text {quartet } & 2075[30] & 2186 & 2184 & 2181 \\ \mathrm{Ta}(\mathrm{CO})_{7}{ }^{+} & \text {singlet } & 2056,2067, & 2165,2171, & 2163,2170, & 2159,2168, \\ & & 2089,2113, & 2189,2211, & 2188,2211 & 2184,2207 \\ & & 2168[25] & 2274 & 2273 & 2270 \\ \mathrm{~W}(\mathrm{CO})_{6} & \text { singlet } & 2000[19] & 2095 & 2091 & 2087 \\ \mathrm{Os}(\mathrm{CO})_{5} & \text { singlet } & 2008, & 2097,2137 & 2094,2134 & 2089,2132 \\ & & 2046[17] & & & \end{array}$


Table 4. Electronic ground states and experimental and theoretical frequencies $\left(\mathrm{cm}^{-1}\right)$ for metal carbonyl complexes computed using DFT/M06-L.

\begin{tabular}{|c|c|c|c|c|c|}
\hline Complex & Spin State & Experiment & $\begin{array}{l}\text { LANL2DZ } \\
\text { TZP }\end{array}$ & $\begin{array}{l}\text { LANL2TZ } \\
\text { TZP }\end{array}$ & $\begin{array}{l}\text { Def2-TZVP } \\
\text { TZP }\end{array}$ \\
\hline $\mathrm{Ti}(\mathrm{CO})_{6}^{+}$ & quartet & 2110 [30] & 2166 & 2161 & 2163 \\
\hline \multirow[t]{2}{*}{$\mathrm{V}(\mathrm{CO})_{6}^{+}$} & triplet & 2097 [29] & 2145,2167 & 2146,2164 & 2145,2167 \\
\hline & & & 2171 & 2167 & 2170 \\
\hline \multirow[t]{2}{*}{$\mathrm{V}(\mathrm{CO})_{6}$} & doublet & 1989 [20] & 2052,2055 & 2053,2056 & 2048,2057 \\
\hline & & & 2059 & 2060 & 2060 \\
\hline $\mathrm{Cr}(\mathrm{CO})_{6}$ & singlet & $2000[8]$ & 2065 & 2060 & 2062 \\
\hline $\mathrm{Mn}(\mathrm{CO})_{6}^{+}$ & singlet & 2115 [26] & 2170 & 2172 & 2169 \\
\hline $\mathrm{Fe}(\mathrm{CO})_{5}{ }^{+}$ & doublet & 2123 [34] & 2179,2185 & 2179,2185 & 2176,2188 \\
\hline \multirow[t]{2}{*}{$\mathrm{Fe}(\mathrm{CO})_{5}$} & singlet & 2016 , & 2075,2098 & 2075,2098 & 2068, 2099 \\
\hline & 2038 [9] & & & & \\
\hline \multirow[t]{2}{*}{$\mathrm{Co}(\mathrm{CO})_{5}^{+}$} & singlet & 2140 & 2190,2203 & 2193,2203 & 2193,2206 \\
\hline & & $2150[24]$ & & & \\
\hline $\mathrm{Ni}(\mathrm{CO})_{4}$ & singlet & 2061 [12] & 2097 & 2107 & 2108 \\
\hline \multirow[t]{2}{*}{$\mathrm{Ni}(\mathrm{CO})_{5}^{+}$} & doublet & 2169 & 2213,2239 & 2211,2235 & 2209,2237 \\
\hline & & 2183 [33] & & & \\
\hline $\mathrm{Cu}(\mathrm{CO})_{4}^{+}$ & singlet & 2198 [28] & 2251 & 2247 & 2246 \\
\hline $\mathrm{Y}(\mathrm{CO})_{8}^{+}$ & singlet & 2087 [31] & 2146 & 2145 & 2145 \\
\hline $\mathrm{Zr}(\mathrm{CO})_{6}^{+}$ & quartet & 2094 [30] & 2159 & 2154 & 2147 \\
\hline \multirow[t]{2}{*}{$\mathrm{Nb}(\mathrm{CO})_{7}^{+}$} & singlet & 2057,2075 & 2130,2136 & 2128,2133 & 2125,2133 \\
\hline & & 2100,2125 & 2152,2171 & 2150,2169 & 2150,2174 \\
\hline
\end{tabular}




$\begin{array}{llllll} & & 2169[25] & 2226 & 2225 & 2227 \\ \mathrm{Mo}(\mathrm{CO})_{6} & \text { singlet } & 2003[18] & 2066 & 2055 & 2059 \\ \mathrm{Ru}(\mathrm{CO})_{5} & \text { singlet } & 2015, & 2070,2102 & 2068,2099 & 2064,2100 \\ & & 2045[16] & & & \\ & & & & 2140 \\ \mathrm{Hf}(\mathrm{CO})_{6}{ }^{+} & \text {quartet } & 2075[30] & 2144 & 2140 \\ \mathrm{Ta}(\mathrm{CO})_{7}{ }^{+} & \text {singlet } & 2056,2067, & 2130,2132, & 2128,2130, & 2121,2125 \\ & & 2089,2113, & 2147,2166, & 2145,2164, & 2141,2162 \\ & & 2168[25] & 2232 & 2230 & 2226 \\ \mathrm{~W}(\mathrm{CO})_{6} & \text { singlet } & 2000[19] & 2066 & 2065 & 2051 \\ \mathrm{Os}(\mathrm{CO})_{5} & \text { singlet } & 2008, & 2069,2107 & 2074,2089 & 2056,2100 \\ & & 2046[17] & & & \end{array}$


Table 5. Frequency scaling factors suitable for fundamental $\mathrm{C}-\mathrm{O}$ vibrations and $\mathrm{rms}\left(\mathrm{cm}^{-1}\right)$

\begin{tabular}{lll}
\hline \multicolumn{1}{c}{ Method } & Scaling Factor & rms \\
\hline B3LYP/LANL2DZ & 0.966 & 6.8 \\
B3LYP/LANL2TZ & 0.966 & 7.2 \\
B3LYP/Def2-TZVP & 0.968 & 7.5 \\
BP86/LANL2DZ & & \\
BP86/LANL2TZ & 1.009 & 7.0 \\
BP86/Def2-TZVP & 1.010 & 8.3 \\
& 1.012 & 8.2 \\
M06/LANL2DZ & & \\
M06/LANL2TZ & 0.952 & 6.2 \\
M06/Def2-TZVP & 0.953 & 6.2 \\
& 0.953 & 9.1 \\
M06-L/LANL2DZ & 0.972 & 8.9 \\
M06-L/LANL2TZ & 0.973 & 7.7 \\
M06-L/Def2-TZVP & 0.974 &
\end{tabular}




\section{Figure Captions}

Figure 1. The experimental infrared spectrum of $\mathrm{Co}(\mathrm{CO})_{5}{ }^{+}[23]$ compared to the spectra predicted by different functionals using the optimized scaling factors derived in this study.

Figure 2. The experimental infrared spectrum of $\mathrm{Ta}(\mathrm{CO})_{7}{ }^{+}[24]$ compared to the spectra predicted by different functionals using the optimized scaling factors derived in this study. 
Figure 1
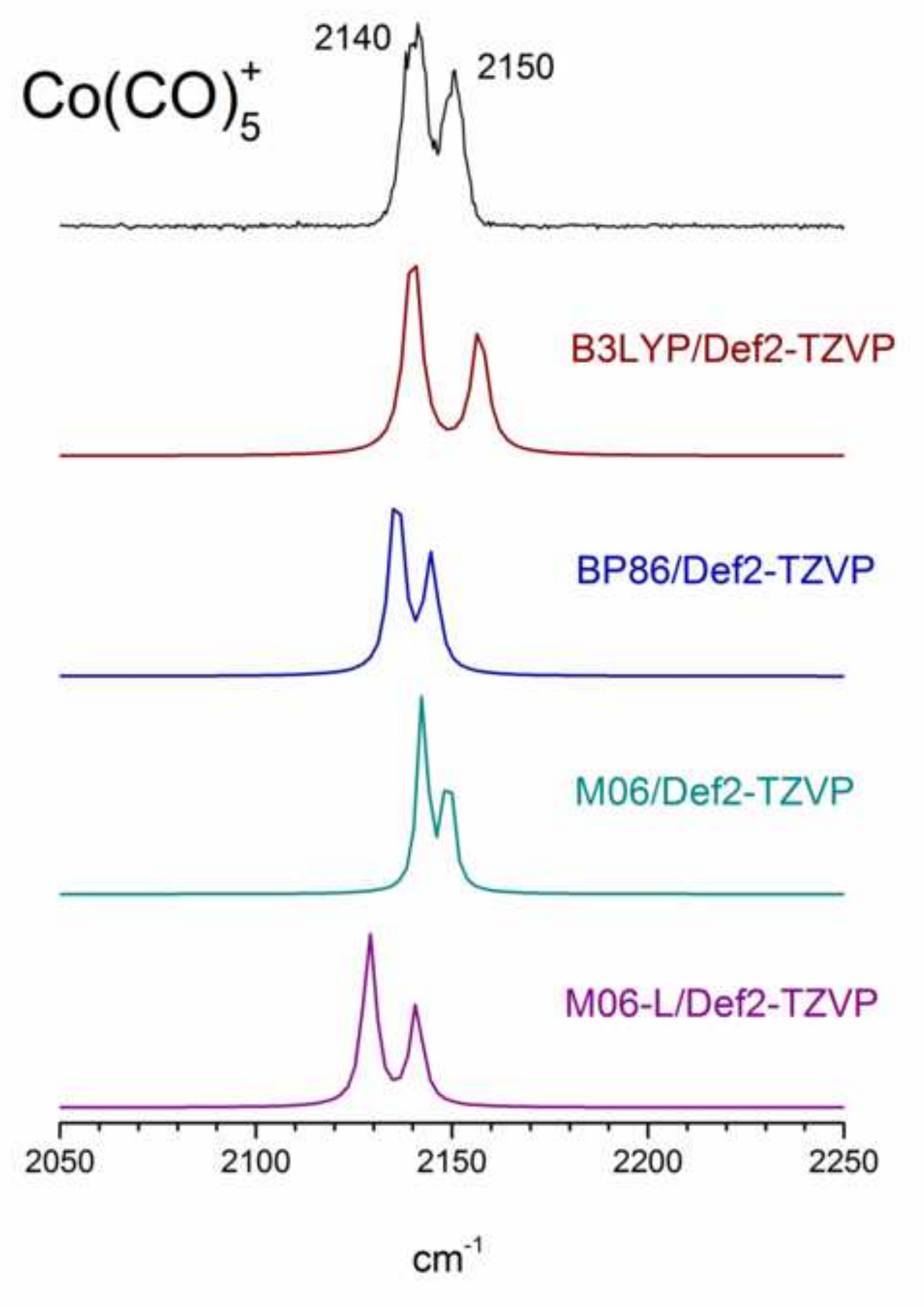

.

.

Eigure
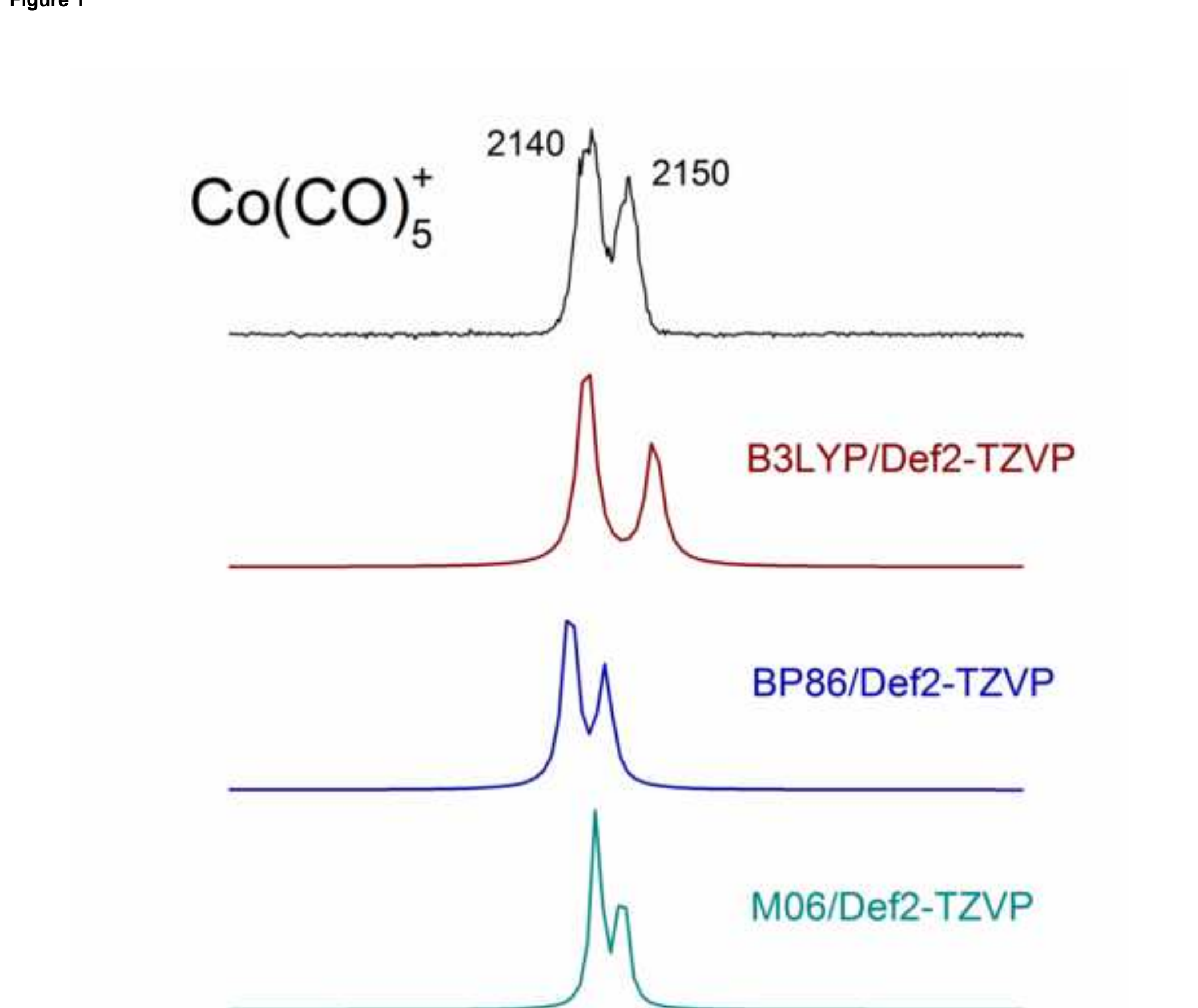


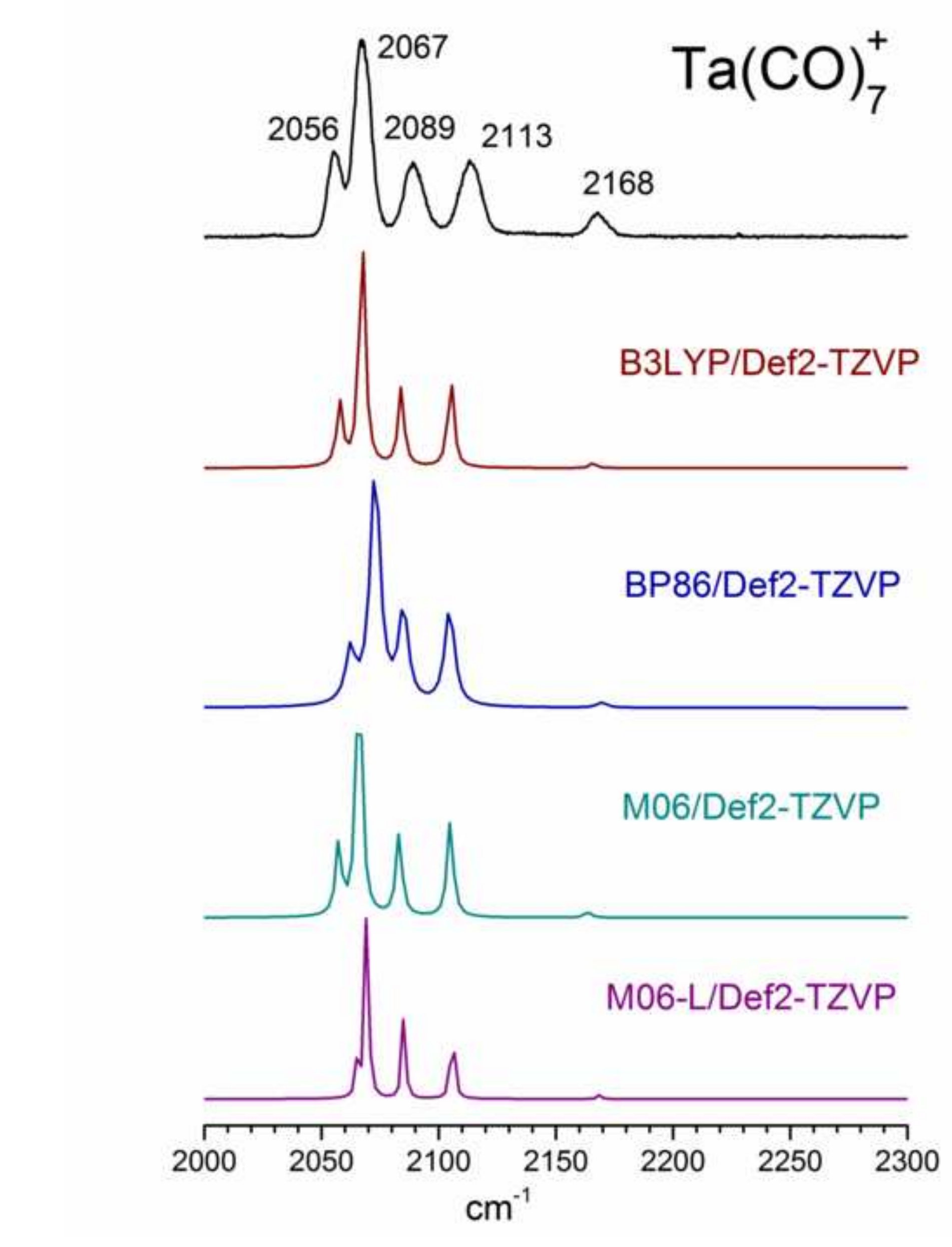

Figure 2

2

2

Figure 2

.

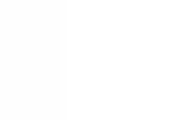
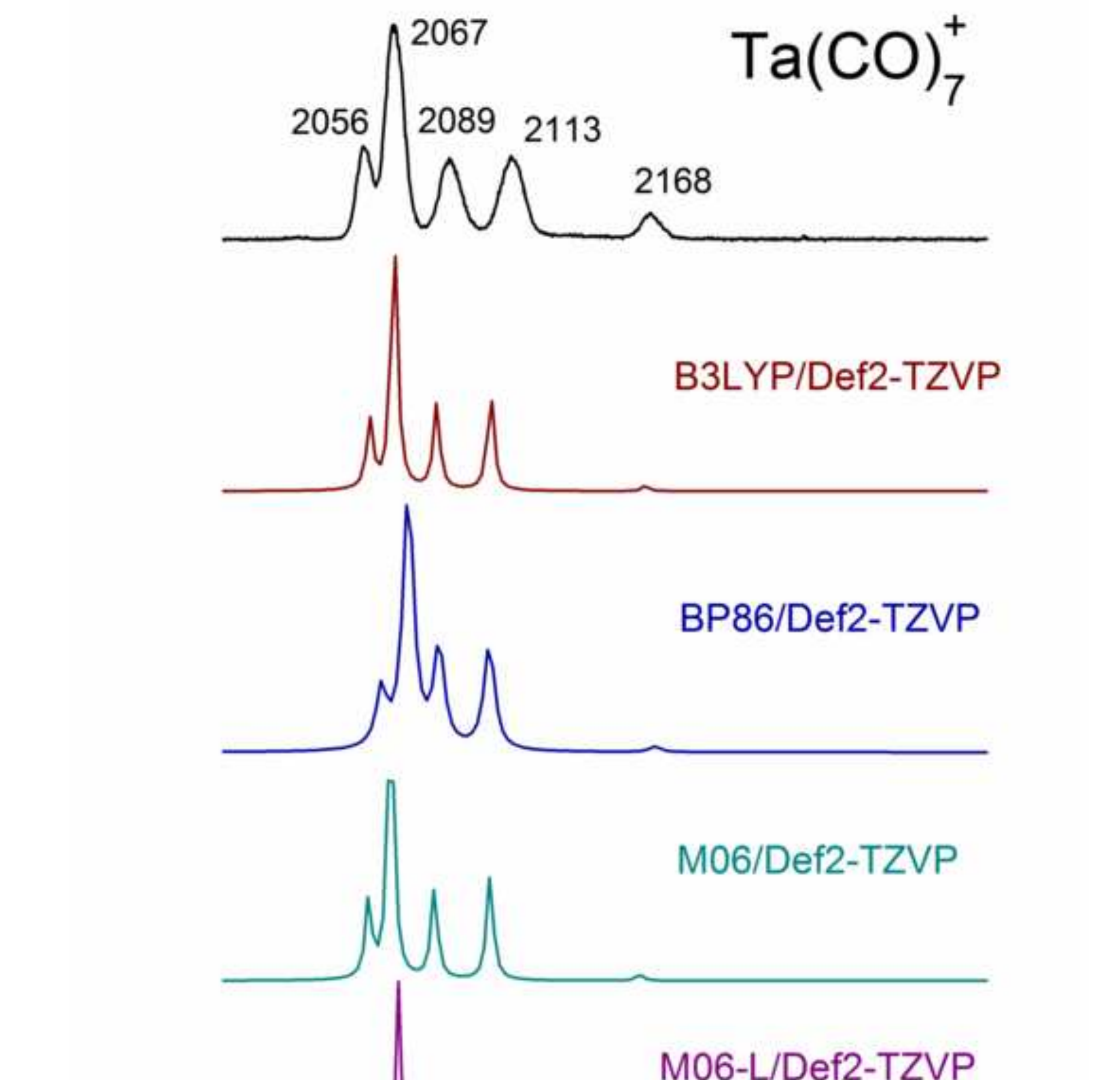


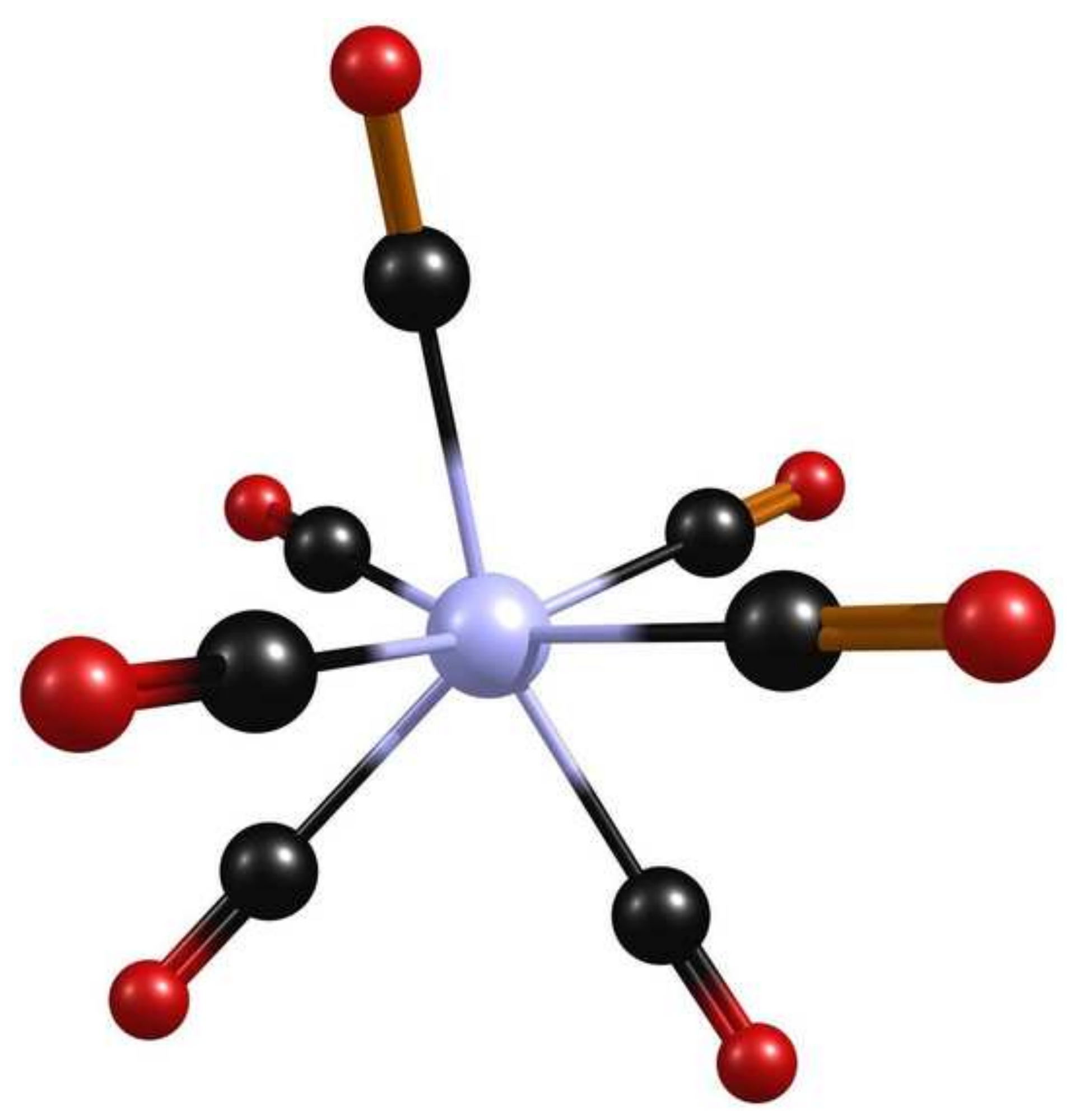

